\title{
Araştırma Makalesi / Research Article \\ Karstik Bölgelerde Bulunan İçme Suyu Şebekelerinde Fiziki Su Kayıplarının Gürültü Korelatörleri ve Basınç Optimizasyonu ile Yönetimi
}

\author{
Tuğba AKDENiz \\ ASAT Genel Müdürlüğü, SCADA Şube Müdürlüğü, Antalya. \\ e-posta: tugbaakdeniz78@gmail.com ORCID ID: https://orcid.org/0000-0003-4013-2457 \\ Geliş Tarihi: 02.12.2020 Kabul Tarihi: 18.02.2021
}

Öz

Küresel ısınma, nüfus artışı, artan temiz ve güvenilir içme suyu ihtiyacı su kaynakları üzerinde negatif bir baskı yaratmaktadır. Bu nedenle, içme suyu şebekelerinde oluşan özellikle fiziki su kayıpları günümüzde

Anahtar kelimeler

Su Kayıpları; Akustik

Dinleme; Basınç

Yönetimi; İçme Suyu

Şebekeleri; Karstik Akiferler artan bir öneme sahiptir. Fiziki kayıpların yönetiminde akustik dinleme yöntemi yaygın olarak kullanılmaktadır. Karstik akiferlerde gözenekli ve geçirgen zemin yapısı nedeniyle içme suyu şebekesinde oluşan sızıntılarının tamamı yüzeye çıkmamakta ve oluşan arızaların tespiti güçleşmektedir. Bu çalışmada; Antalya içme suyu şebekesinde fiziki su kayıplarının yönetimi amacı ile bir alt bölge oluşturulmuş ve bu alt bölgede sabit tip gürültü korelatörleri ile uzun süreli akustik dinleme ve basınç optimizasyonu çalışmaları yapılmıştır. Çalışma sonuçları karstik akiferlerde uzun süreli akustik dinleme yönteminin portatif cihazlarla yapılan çalışmalara nazaran fiziksel su kayıplarının yönetiminde etkili bir araç olduğunu göstermiştir. Çalışma bölgesinde $\% 52$ seviyesinde olan su kayıpları; basınç optimizasyonu ve gürültü korelatörleri ile akustik dinleme yöntemleri kullanılarak \% 15 seviyesine düşürülmüştür.

\section{Physical Water Loss Management in Drinking Water Networks of Karst Regions using Leak Noise Correlators and Pressure Optimization}

\begin{abstract}
Global warming, population growth and increasing need for clean and safe drinking water, create a negative pressure on water resources. For this reason, especially physical water losses in drinking water networks have an increasing importance today. Acoustic listening method is widely used in the management of physical losses. Due to the porous and permeable ground structure in karstic aquifers, all of the leaks in the drinking water network do not come to the surface and the detection of the malfunctions that occur becomes more difficult. In this study; a sub-region was created in Antalya drinking water network for the management of physical water losses, and long-term acoustic listening and pressure optimization studies were carried out with fixed-type noise correlators in this sub-region. The results of the study showed that the long-term acoustic listening method in karstic aquifers is an effective tool in the management of physical water losses compared to the studies performed with portable devices. By using pressure optimization, noise correlators and acoustic listening methods, the water losses at the level of $52 \%$ was reduced to $15 \%$ in the study area.
\end{abstract}

(C) Afyon Kocatepe Üniversitesi

\section{Giriş}

Günümüzde azalan su kaynakları ve artan temiz içme suyu ihtiyacı içme suyu şebekelerinde oluşan su kayıplarına daha fazla önem verilmesine neden olmaktadır. Bu kapsamda, Ülkemizde 2014 yılında "İçme Suyu Temin ve Dağıtım Sistemlerindeki Su Kayıplarının Kontrolü Yönetmeliği" yürürlüğe alınmıştır. Iilgili yönetmelikte içme suyu şebekelerinde su kayıplarının azaltılması ve önlenmesi açısından yapılması gereken çalışmalar belirtilmekte olup şebekenin uzaktan izleme ve kontrolüne olanak sağlayan SCADA sistemlerinin kurulmasına ile fiziki kayıpların azaltılması konularına büyük önem verilmektedir (SKKY 2014). İçme suyu şebekelerinde oluşan su kayıpları idari ve fiziksel su kayıpları olmak üzere 2'ye ayrılmakta ve farklı alt bileşenlerden oluşmaktadır (Şekil 1). 


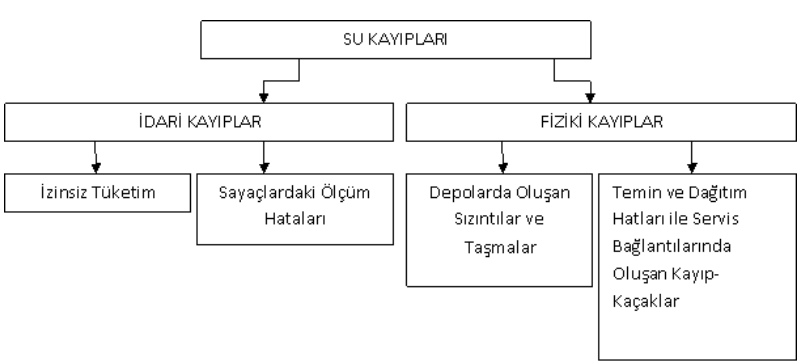

Şekil 1. İçme suyu şebekelerinde oluşan su kayıpları (IWA 2018)

İçme suyu şebekelerinde sadece basınç yönetimi ile fiziki su kayıplarının azaltılması mümkündür ve bu konuda literatürde pek çok çalışma bulunmaktadır (Karadirek vd. 2012, Gupta ve Kulat 2018, Adedeji vd. 2018). Akustik dinleme yöntemleri ise uzun yıllardır su kuruluşları tarafından uygulanan bir yöntemdir. Liv vd. tarafından yapılan çalışmada bu yönteme ilişkin detaylı bilgi ve öneriler sunulmaktadır (Li 2015). Benzer şekilde geçmiş yıllarda farklı araştırmacılar tarafından akustik dinleme yöntemlerinin verimliliği ve geliştirilmesi hakkında detaylı çalışmalar yapılmıştır (Hunaidi ve Wang 2006, Sánchez 2005). Ancak, özellikle ülkemizde yapılan çalışmalarda gürültü kaydediciler sabit olarak yerinde bırakılmamış ve uzun süreli takibi yapılmamıştır. Bu çalışma kapsamında sabit tip gürültü kaydediciler kullanılarak Antalya karstik bölgesinde su temin ve dağıtım hatları ile servis bağlantılarında oluşan sızıntılar üzerine yoğunlaşılmıştır.

\section{Materyal ve Metot}

\subsection{Pilot çalışma bölgesi}

Antalya ili Türkiye' nin nüfus sayısına göre 5. büyük ili olup önemli bir turizm merkezidir (IntKyn. 1). 2018 yılı verilerine göre şehir merkezinde içme suyu üretimi 140.412.955 $\mathrm{m}^{3} / \mathrm{yll}$ olup su kayıpları oranı \% $37,45^{\prime}$ dir (IntKyn. 2). Türkiye'nin en büyük karstik bölgelerinden biri olan Antalya ilinin şehir merkezinde zemin yapısı travertendir (Şekil 2 ve Şekil 3). Geçirgen zemin yapısı nedeni ile Antalya içme suyu şebekesinde oluşan sızıntılar zaman zaman yüzeye çıkmamaktadır. Bu durum sızıntıların tespitini zorlaştırmakta ve tespit süresini uzatmaktadır.

Bu çalışma kapsamında; Antalya merkez içme suyu şebekesinde vana, boru, boru arıza sıklığı, yaklaşık nüfus ve abone sayısı gibi şebeke bileşenleri ve yapısı göz önüne alınarak Kültür mahallesi pilot çalışma bölgesi olarak seçilmiş ve Kültür DMA olarak isimlendirilmiştir (Şekil 4).

Kültür DMA girişinde bulunan SCADA noktasında debimetre ve basınçmetre bulunmakta olup alt bölge bağımsız olarak çalışmaktadır. Endress Hauser marka basınçmetreler \%0,5 oranında hassasiyete, Siemens marka debimetreler ise \%0,2 oranında hassasiyete sahiptir. Çalışma bölgesi üniversite ve hastaneye yakın olup yurt, pansiyon, öğrenci evlerinin ağırlıklı olduğu bir bölgedir. Çalışma bölgesi şebeke ana boru uzunluğu yaklaşık olarak $20 \mathrm{~km}$, abone sayısı 10.000'dir.

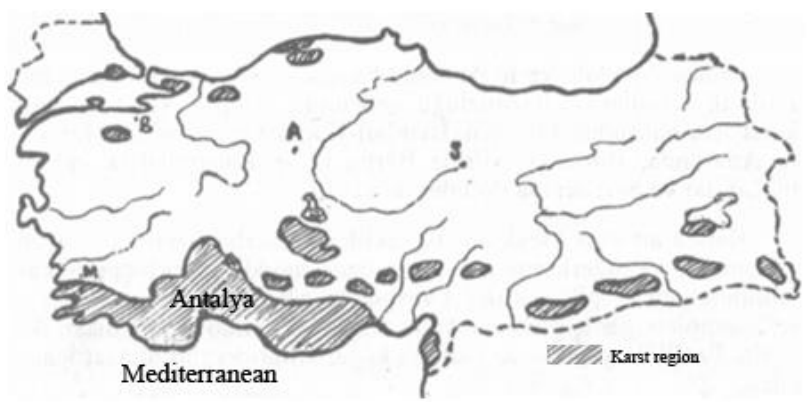

Şekil 2. Türkiye'de bulunan karstik bölgelerin şematik görüntüsü (Inan 1985) 


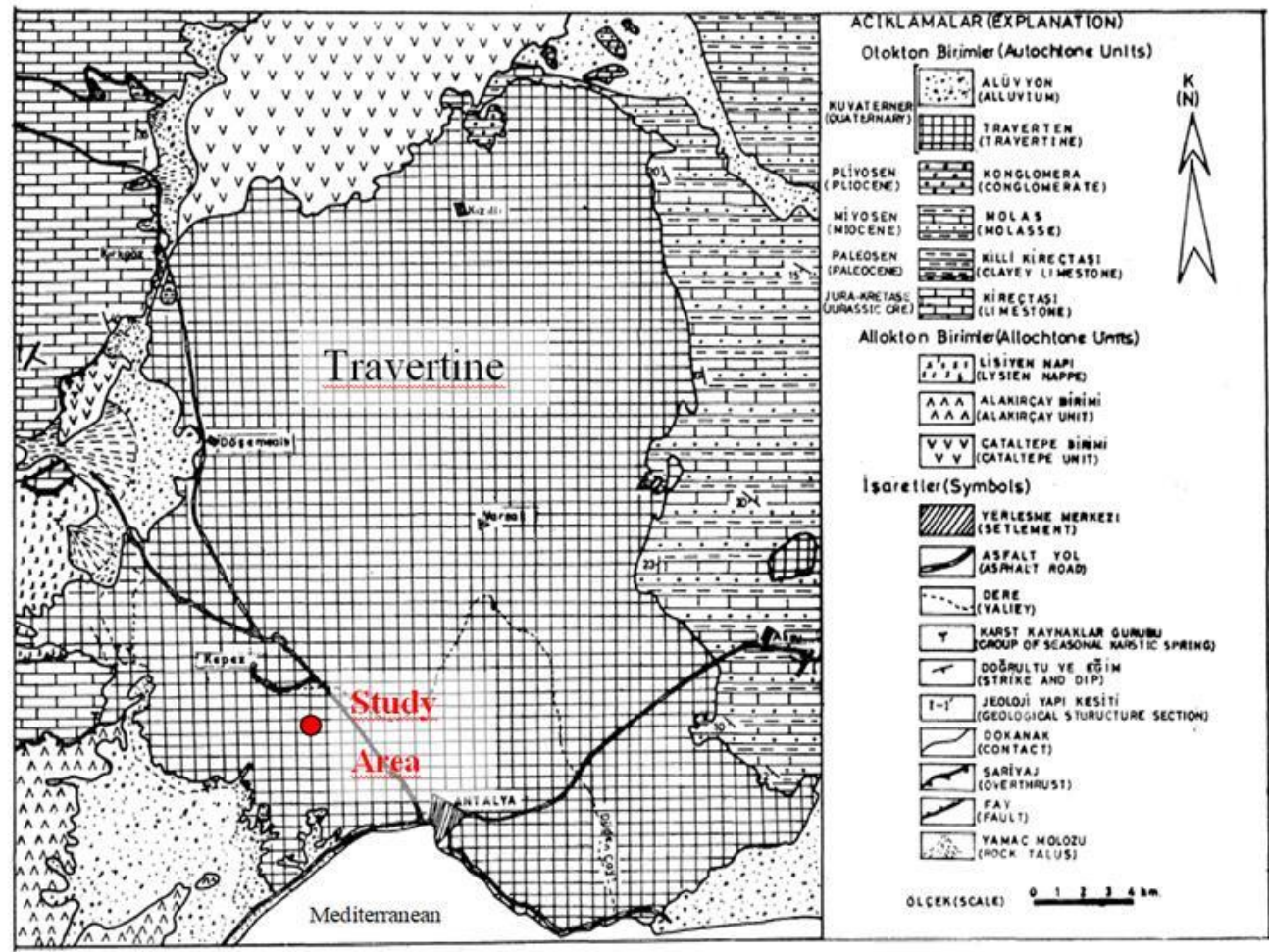

Şekil 3. Antalya merkezi jeoloji haritası ve çalışma bölgesinin şematik gösterimi

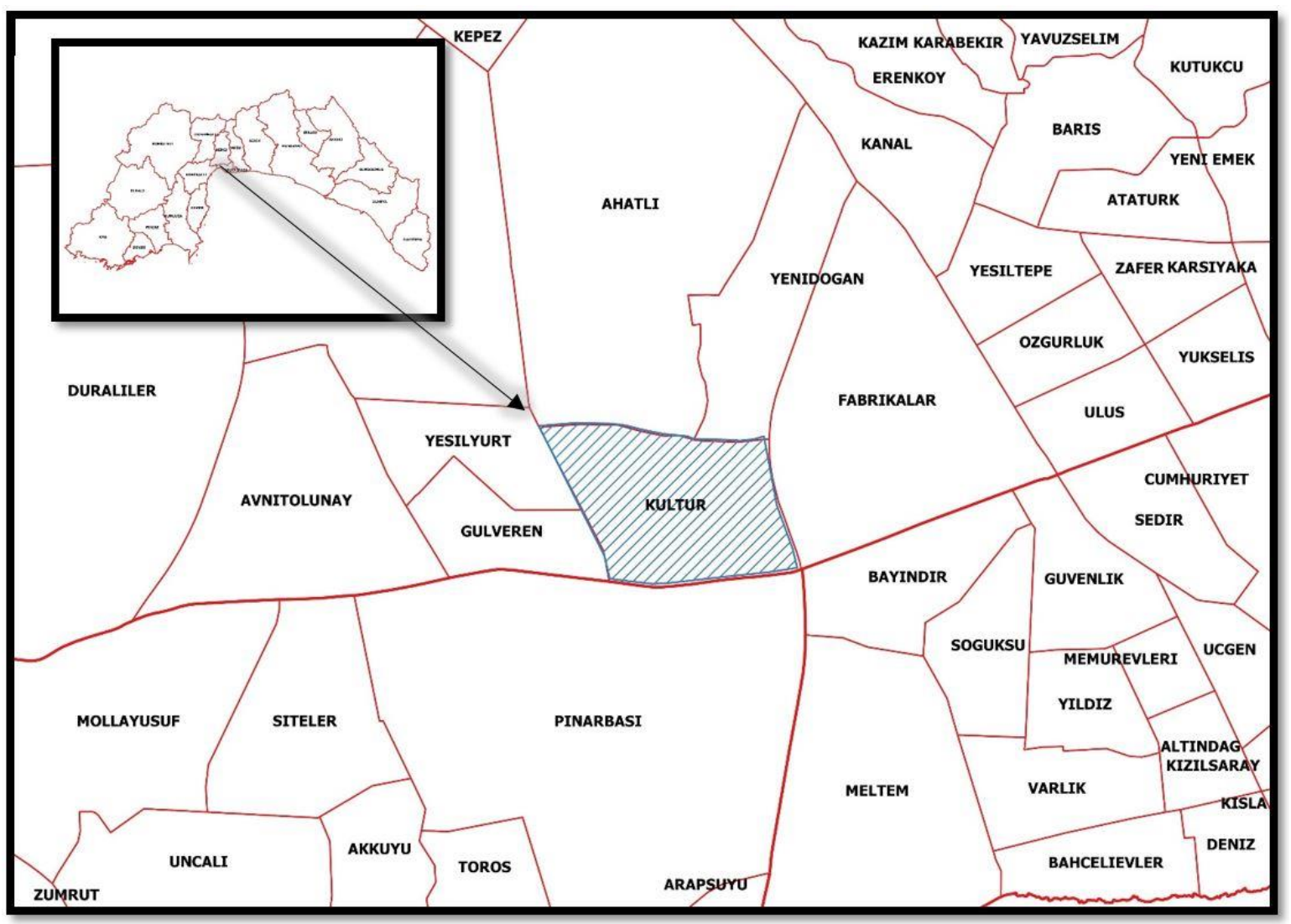

Şekil 4. Çalışma bölgesinin Antalya ilindeki lokasyonu ve SCADA noktası

\section{2 Çalışma bölgesi için su bütçesi}

Çalışma kapsamında ilk olarak Kültür DMA'da su kayıpları seviyelerinin tespiti için su bütçesi oluşturulmuştur. Su bütçesi oluşturulurken sisteme verilen su miktarı alt bölge girişinde bulunan ve anlık debi ölçümü yapan SCADA ölçüm noktasından elde 
edilmiştir. Sisteme verilen toplam su miktarı ve izinli tüketim miktarı arasındaki fark kullanılarak alt bölge için Ocak, Şubat ve Mart 2018 dönemleri için su kayıpları oranı ortalama $\% 57,04$ olarak hesaplanmıştır (Çizelge 1).

Çizelge 1. Kültür alt bölgesinde su kayıpları (Ocak-ŞubatMart 2018)

\begin{tabular}{cccc}
\hline 2018 & $\begin{array}{c}\text { İzinli Su } \\
\text { Tüketimi } \\
\left(\mathrm{m}^{3} / \mathrm{ay}\right)\end{array}$ & $\begin{array}{c}\text { Sisteme Verilen } \\
\text { Su } \\
\left(\mathrm{m}^{3} / \mathrm{ay}\right)\end{array}$ & $\begin{array}{c}\text { Su Kayıpları } \\
(\%)\end{array}$ \\
\hline Ocak & 80.916 & 167.400 & 51,66 \\
\hline Şubat & 61.810 & 153.888 & 59,83 \\
\hline Mart & 68.481 & 169.632 & 59,63 \\
\hline \multicolumn{5}{c}{ Ortalama } & 57,04
\end{tabular}

\subsection{Gürültü korelatörleri ile akustik dinleme}

Çalışma kapsamında mıknatıs ile boru yüzeyine tutunan ve radyo frekansı ile haberleşen gürültü kaydedici 30 adet korelatör kullanılmıştır. Çalışma bölgesi için uzunluk, çap, cins, koordinat, imalat tarihi gibi boru bilgileri ASAT CBS sistemi verilerine dayanılarak yazılıma eklenmiştir. Gürültü kaydedici korelatörler; hat vanalarına yerleştirilmiştir. Ayrıca çalışma sahası ile haberleşmeyi sağlamak için elektrik direkleri, yüksek binalar ve anten direklerine ek yükseltici antenler yerleştirilmiştir (Şekil 5).

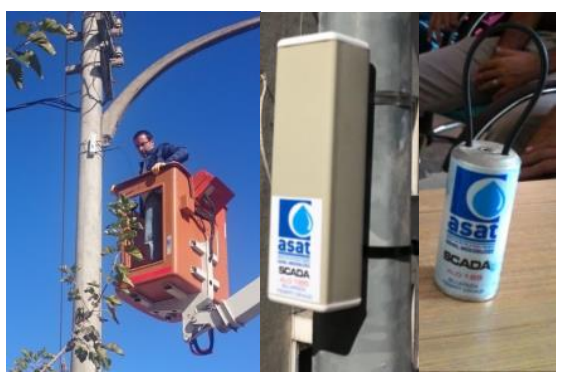

Şekil 5. Sahaya yerleştirilen yükseltici antenler ve çalışmada kullanılan gürültü korelatörleri

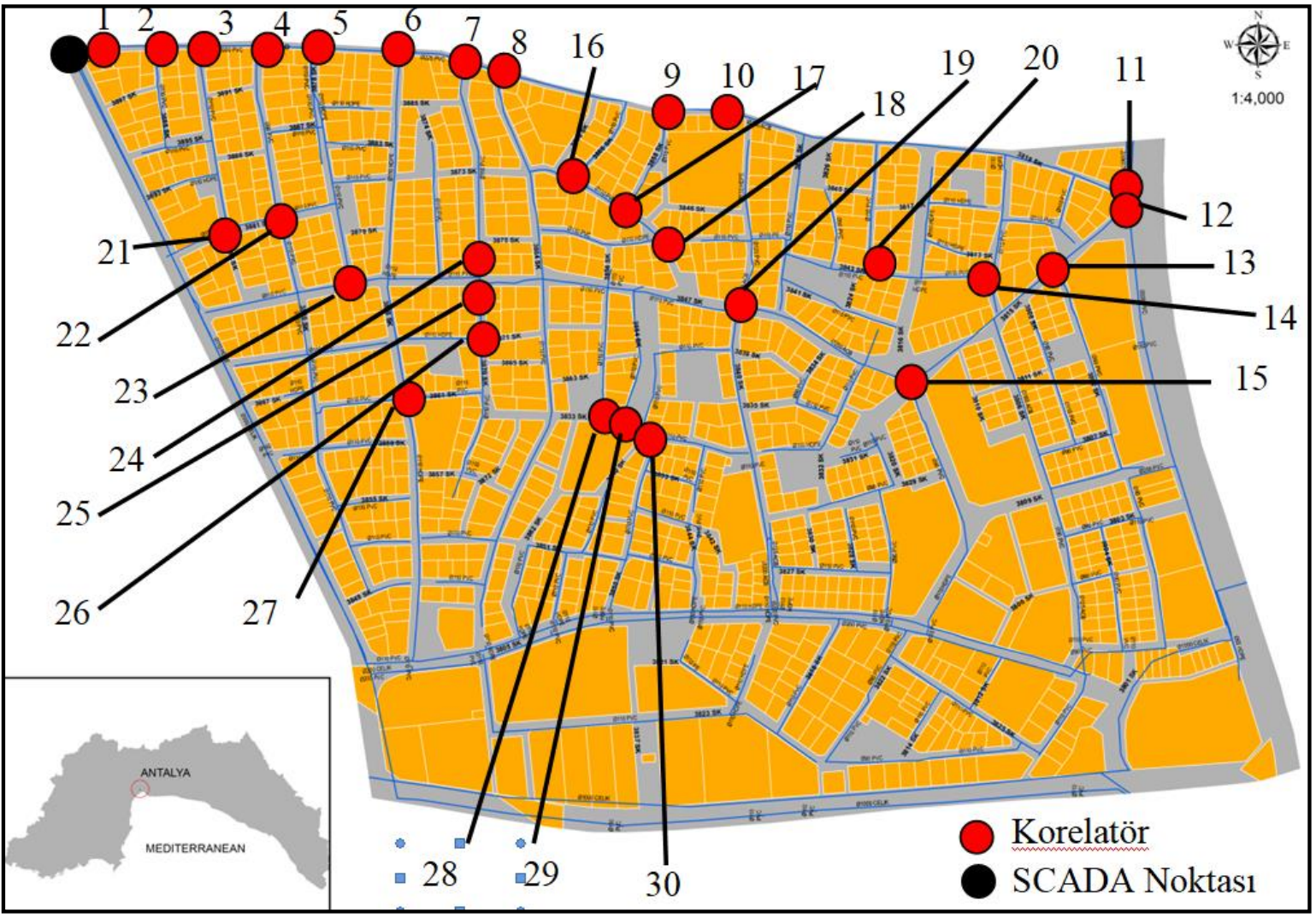

Şekil 6. Gürültü kaydedici korelatörlerin ve SCADA noktasının konumları 
Ticari bir yazılım ile bu cihazlardan temin edilen verilerden arıza noktalarının vanalara mesafesi tespit edilmiştir. Yazılım ekran görüntüsü Şekil 7'de sunulmaktadır. Yazılım ile su kayıplarının oranlarına bağlı olarak farklı renklerde alarmlar tanımlanabilmektedir.

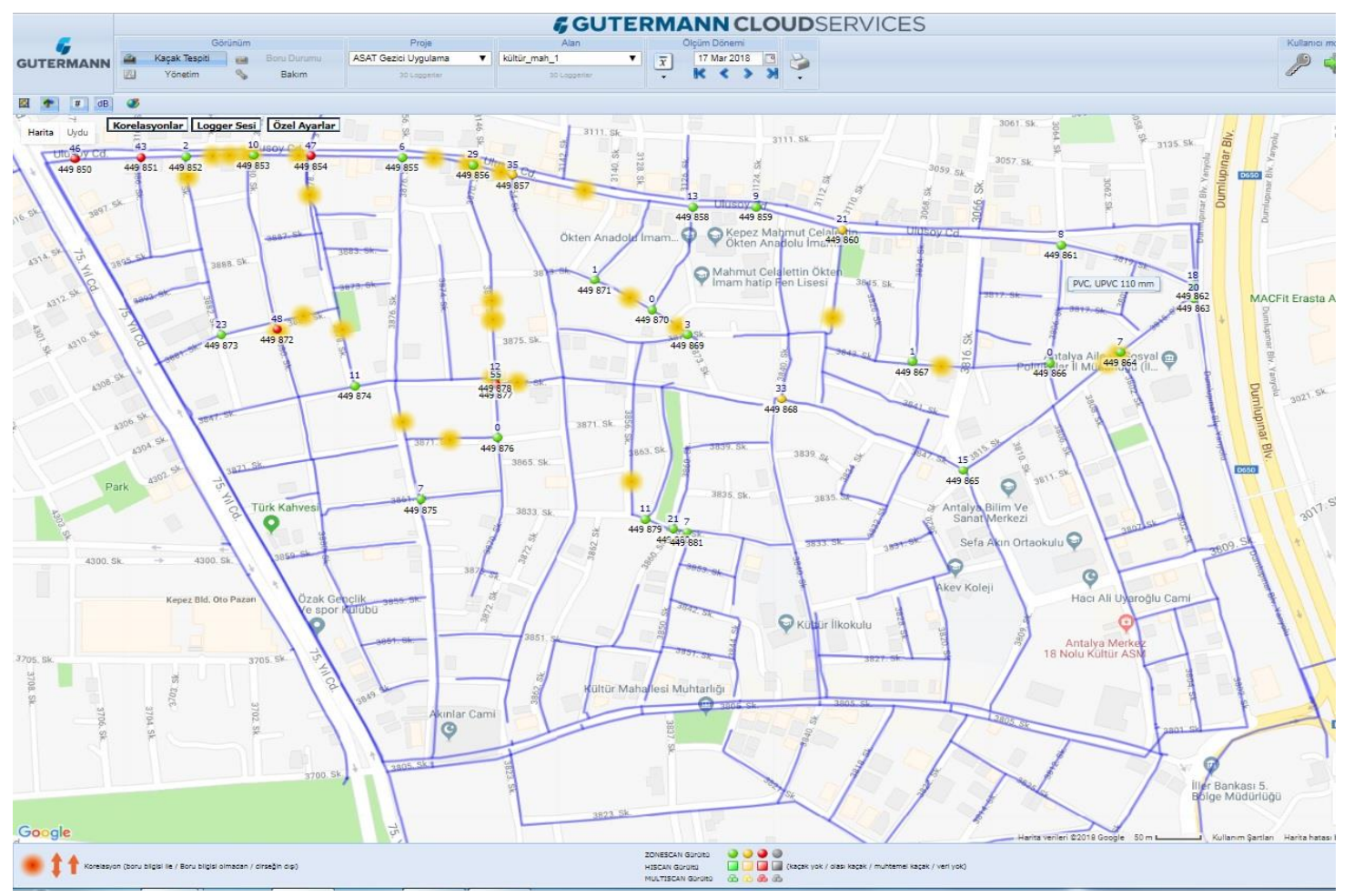

Şekil 7. Yazılım ekran görüntüsü

\section{Bulgular}

\subsection{Gürültü kaydedici korelatör kullanılarak yapılan çalışmalar}

Çalışma kapsamında bölgede 10 günlük süre içerisinde 20 adet sızıntı noktası belirlenmiş ve giderilmiştir. Bu noktalarda tespit edilen arızalar ağırlıklı olarak yüzeye çıkmayan sızıntılardır. Bu sızıntıların çalışma bölgesinin zemin yapısı nedeni ile kısa vadede tespit edilebilmesi güçtür. Yüzeyde görünmeyen ancak gürültü kaydedici korelatörler kullanılarak tespit edilen bir arızaya ait fotoğraf Şekil 8 'de sunulmaktadır. Tespit edilen arızalar tamir edildikten sonra bölgedeki minimum gece debisi $205 \mathrm{~m}^{3}$ /saat'ten $130 \mathrm{~m}^{3}$ /saat'e düşmüştür (Şekil 9). Yapılan çalışma sonucunda bölgedeki \%57

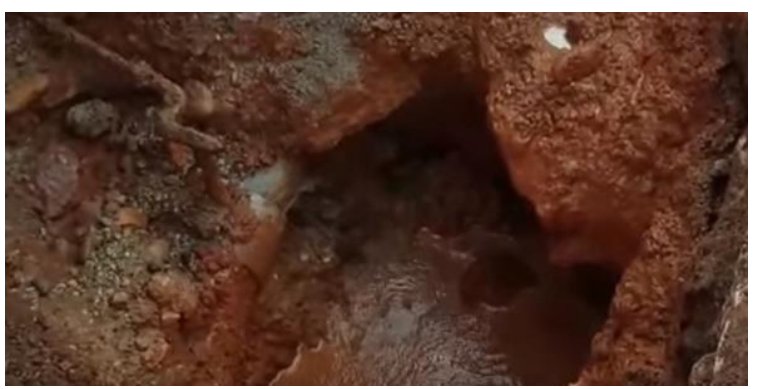

Şekil 8. Tespit edilen boru sızıntıları için örnek

Çizelge 2. Kültür DMA için su kayıpları (Nisan 2018)

\begin{tabular}{cccc}
\hline 2018 & $\begin{array}{c}\text { İinli Su Tüketimi } \\
\left(\mathrm{m}^{3} / \mathrm{ay}\right)\end{array}$ & $\begin{array}{c}\text { Sisteme } \\
\text { Verilen Su } \\
\left(\mathrm{m}^{3} / \mathrm{ay}\right)\end{array}$ & $\begin{array}{c}\text { Su } \\
\text { Kayıpları } \\
(\%)\end{array}$ \\
\hline Nisan & 77.159 & 131.040 & 41,12 \\
\hline
\end{tabular}
seviyesindeki su kayıpları \% 41 seviyesine düşürülmüştür (Çizelge 2). 


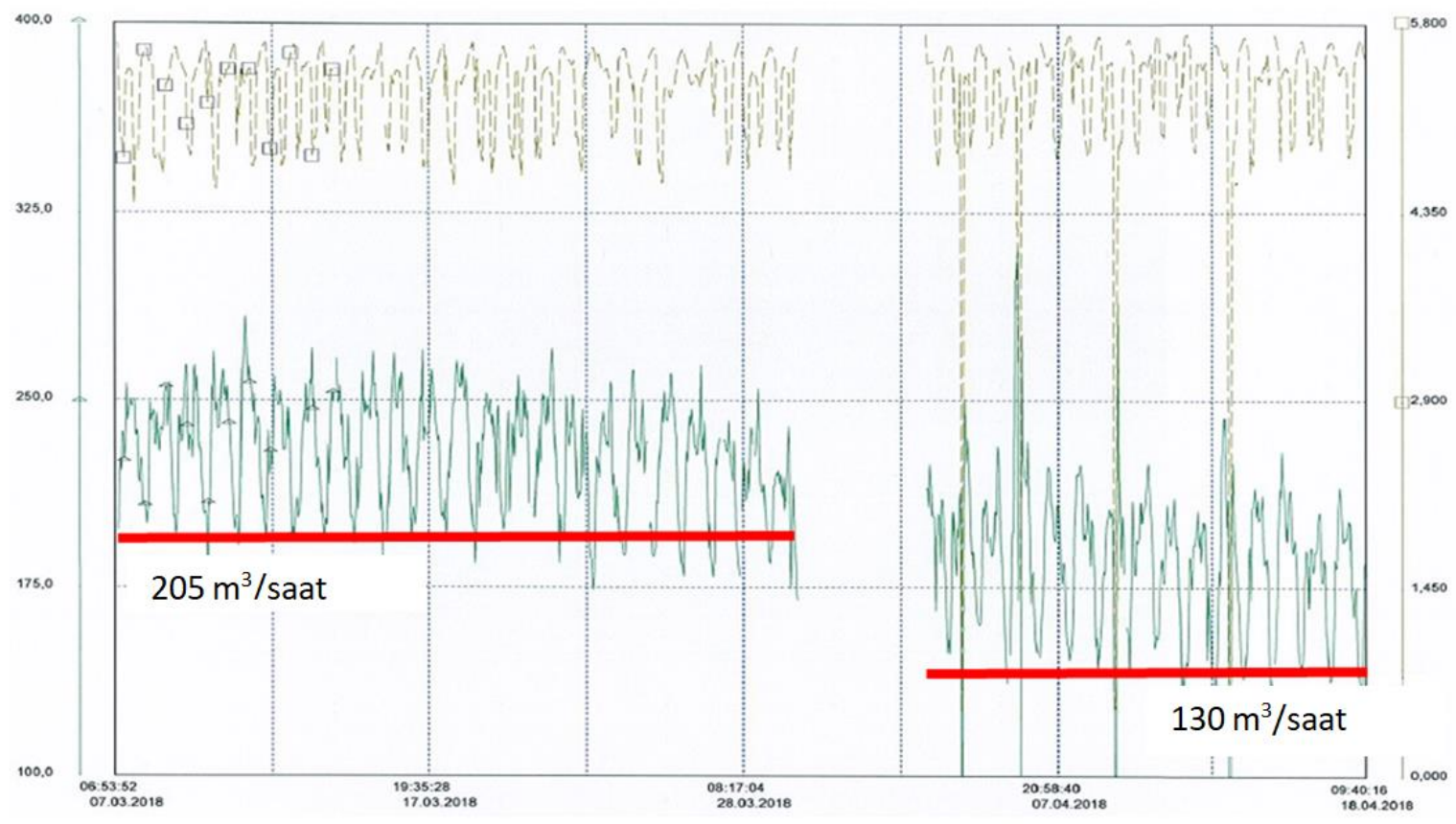

Şekil 9. Kültür DMA minimum gece debisindeki değişim SCADA ekran görüntüsü (07.03.2018-18.04.2018)

\subsection{Basınç kırıcı vana ve gürültü kaydedici korelatör kullanılarak yapılan çalışmalar}

Su kuruluşları tarafından yapılan çalışmalarda genellikle alt bölgelerde dinleme çalışmaları sonucunda belirlenen sızıntı noktalarında gerekli iyileştirme ve tamiratlar yapılarak portatif cihazlar farklı alt bölgelere taşınmaktadır. Ancak bu çalışmada gürültü kaydedici korelatörler sabit ve sürekli olarak aynı alt bölgede çalıştırımaya devam edilmiştir. Böylece, gürültü kaydedici korelatörlerle ile yerleri belirlenen sızıntılar onarıldıktan sonra bu noktaların yakınlarında yeni arızaların oluştuğu ve minimum gece debisinin arttığı görülmüştür. $\mathrm{Bu}$ durum, onarımlar sonrası şebeke basıncının artmasından kaynaklanmakta olup 09.04.201829.05.2018 tarih aralığını gösteren SCADA ekran görüntüsü Şekil 10'da sunulmaktadır.

Minimum gece debisindeki artış, onarım çalışmaları sonrasında şebeke basıncının artması ve buna bağlı olarak yeni boru arızalarının oluşmasından kaynaklanmaktadır. Bu kapsamda Kültür alt bölgesi girişine sabit çıkışlı bir basınç kırıcı vana takılarak DMA girişinde ortalama basınç 5,38 bar seviyesinden 4,14 bar seviyesine düşürülmüştür. Bölgede yaşayan abonelerden herhangi bir basınç şikayeti alınmamıştır. Basınç optimizasyonu öncesi ve sonrasına ait 7 günlük veriler kullanılarak yapılan değerlendirmeye ait sonuçlar Çizelge 3 ve Şekil 11 'de görülmektedir. Böylece, çalışma bölgesindeki su kayıpları \%15 seviyesine düşürülmüştür (Çizelge 4).

Çizelge 3. Basınç kırıcı vana öncesi ve sonrası için ortalama şebeke basınç ve debileri

\begin{tabular}{ccc}
\hline DMA Girişi & $\begin{array}{c}\text { Basınç Kırıcı Vana } \\
\text { Montajı Öncesi } \\
(22.05 .2018- \\
29.05 .2018)\end{array}$ & $\begin{array}{c}\text { Basınç Kırıcı Vana } \\
\text { Montajı Sonrası } \\
(31.05 .2018- \\
06.06 .2018)\end{array}$ \\
\hline Basınç (bar) & 5,38 & 4,14 \\
\hline Debi (m³/saat) & 189,43 & 139,69 \\
\hline $\begin{array}{c}\text { Minimum Gece } \\
\text { Debisi (MNF) } \\
\left(\mathrm{m}^{3} / \text { saat) }\right.\end{array}$ & 144,97 & 88,69 \\
\hline
\end{tabular}

Çizelge 4. Kültür DMA su kayıpları (Haziran 2018)

\begin{tabular}{cccc}
\hline 2018 & $\begin{array}{c}\text { İzinli Su Tüketimi } \\
\text { (m3/ay) }\end{array}$ & $\begin{array}{c}\text { Sisteme } \\
\text { Verilen Su } \\
\text { (m3/ay) }\end{array}$ & $\begin{array}{c}\text { Su Kayıpları } \\
(\%)\end{array}$ \\
\hline Haziran & 74.729 & 87.840 & 14,93 \\
\hline
\end{tabular}




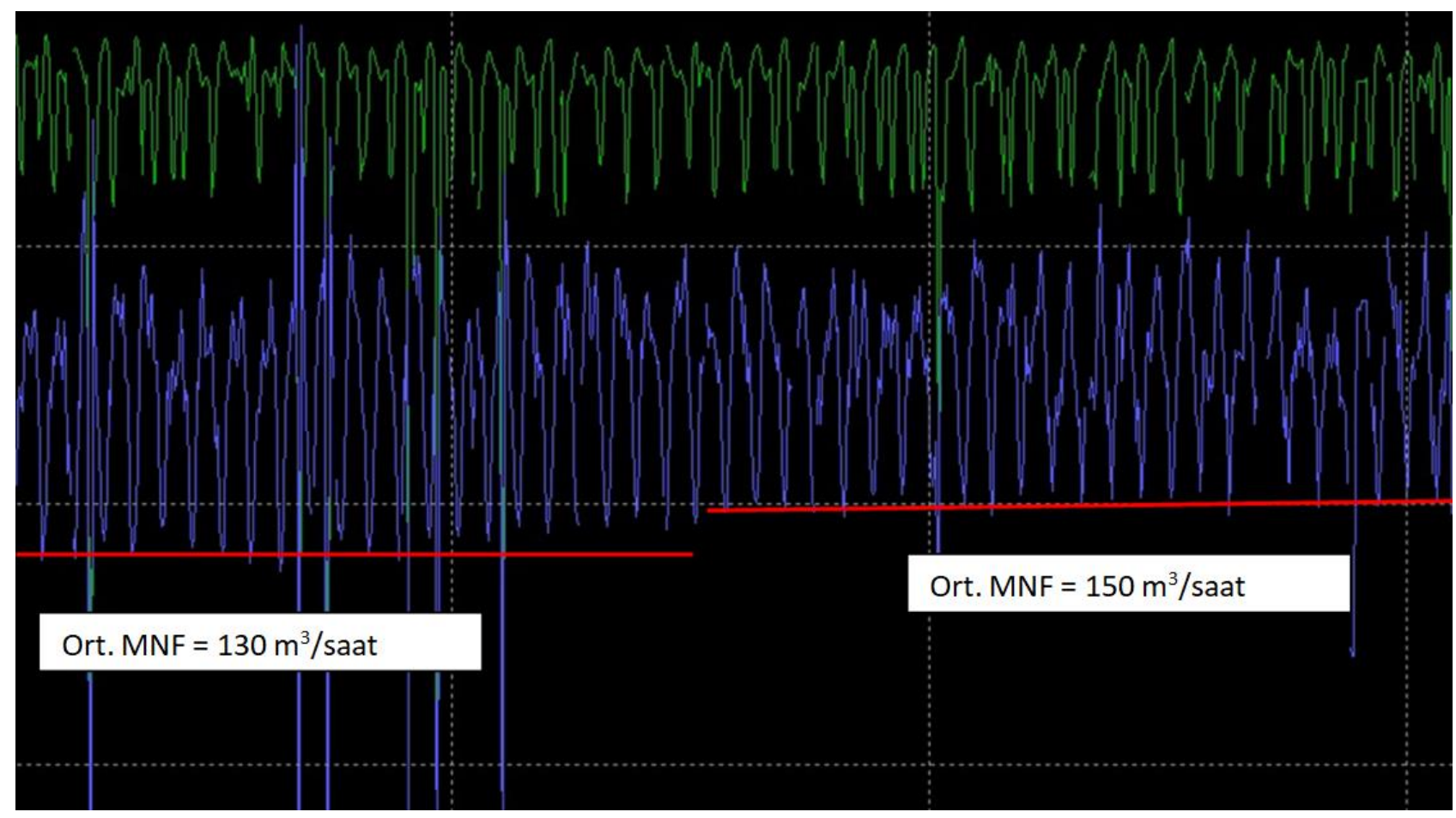

Şekil 10. Uzun dönem SCADA verileri üzerinden MNF artışının belirlenmesi (09.04.2018-29.05.2018)

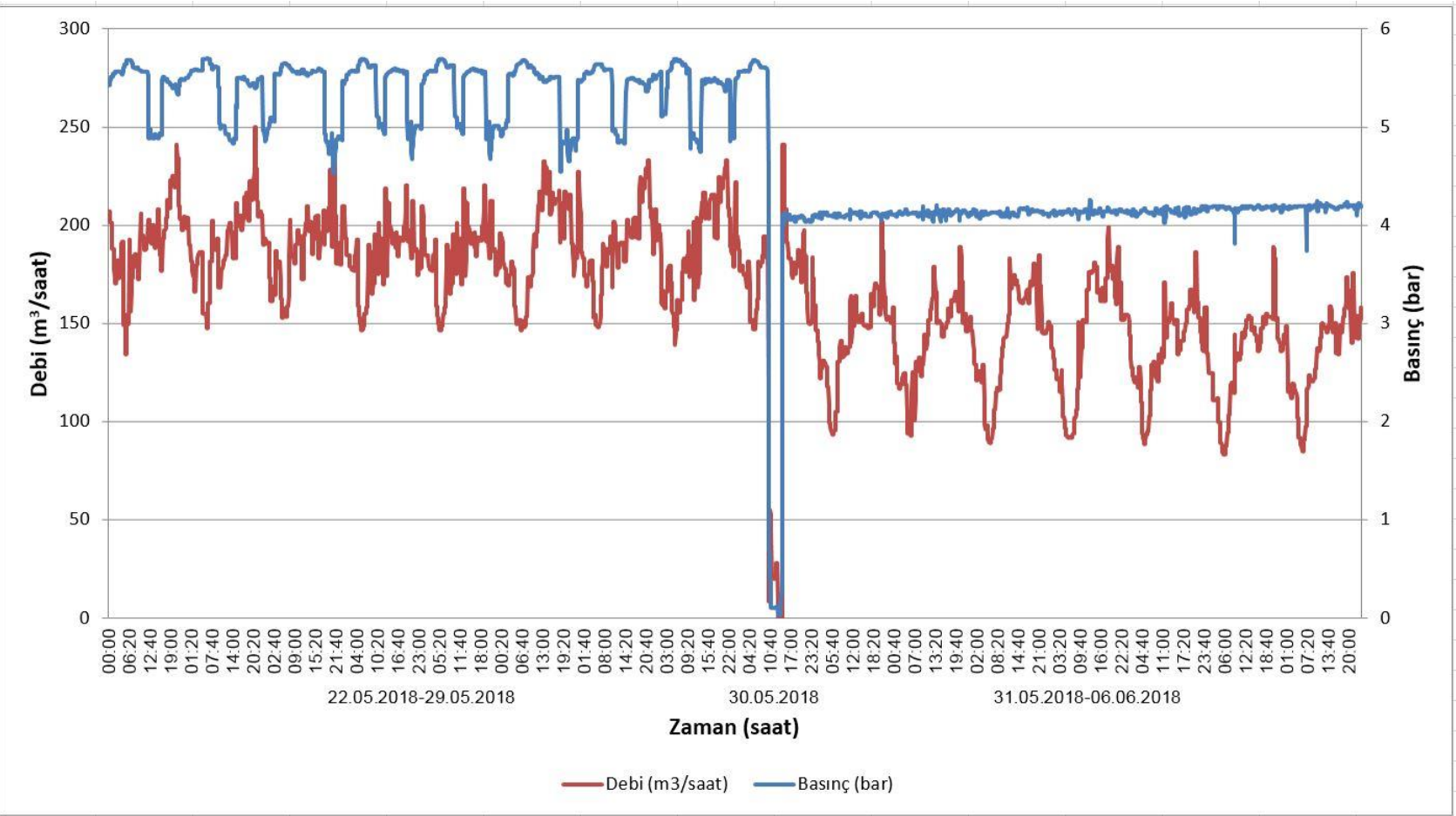

Şekil 11. Basınç kırıcı vana öncesi ve sonrası için 7 günlük şebeke basınç ve debi değişimi

Sistem aktif olarak kullanılmaya devam etmekte olup pilot bölgede oluşan fiziki su kayıpları anlık olarak izlenmekte ve yüksek sızıntı ihtimali olan noktalar alarm olarak sisteme yansımaktadır. Basınç yönetimi sonrasında sistem sayesinde belirlenen sızıntı noktalarında yapılan tamiratlar sonrasında oluşan arıza sıklığının azaldığı görülmüştür. 


\subsection{Fayda-Maliyet Analizi}

Bu çalışma kapsamında detayları sunulan bölge, ASAT Genel Müdürlüğü tarafından gerçekleştirilmiş kapsamlı bir projenin parçası olup yaklaşık maliyeti 300.000 TL'dir. Tasarruf miktarl; sistem ile belirlenen arıza debisi ve su birim fiyatı (en düşük tarife olan hayır kurumları tarifesi 2,84 TL) göz önüne alınarak hesaplanmıştır. Yapılan çalışma ile elde edilen sonuçlar Çizelge 5'de sunulmaktadır.

Çizelge 5. Tespit edilen arıza sayıları ve sistem ile elde edilen kazanç

\begin{tabular}{|c|c|c|}
\hline & $\begin{array}{l}\text { Tespit Edilen } \\
\text { Kayıp Miktarı } \\
\left(\mathrm{m}^{3} / \mathrm{yı}\right)\end{array}$ & $\begin{array}{c}\text { Tespit Edilen Arıza } \\
\text { Sayısı (Adet) }\end{array}$ \\
\hline 2018 & 129,981 & 47 \\
\hline 2019 & 56,130 & 32 \\
\hline 2020 & 9,902 & 12 \\
\hline TOPLAM & 196,014 & 91 \\
\hline $\begin{array}{c}\text { Tasarruf } \\
\text { Miktarı (TL) }\end{array}$ & \multicolumn{2}{|c|}{$558,638.72 \mathrm{TL}$} \\
\hline
\end{tabular}

\section{Tartışma ve Sonuç}

Çalışma kapsamında oluşturulan alt bölgede gürültü kaydedici korelatörler yerleştirilerek fiziki su kayıplarının oluştuğu noktalar tespit edilmiştir. Saha çalışmaları ile sızıntı noktalarında gerekli tamirat, bakım ve iyileştirmeler yapılmıştır. Kurulan sabit tip akustik dinleme ve izleme sistemi aktif olarak çalışmaya devam etmektedir. Bu çalışma kapsamında alt bölgede \%57 seviyesinde olan su kayıpları oranı sadece fiziki su kayıplarının doğru bir şekilde yönetimi ile \%41 seviyesine indirilmiştir. Buna ek olarak gerçekleştirilen basınç optimizasyonu çalışmaları ile çalışma bölgesindeki su kayıpları \%15 seviyesi düşürülmüştür. İlerleyen çalışmalarda fiziki su kayıplarının uluslararası ölçekte kıyaslanmasına ve ifade edilmesine olanak sağlayan ILI (Altyapı Kaçak Indeksi) performans indikatörünün de hesaplanması planlanmakta ve benzer çalışmalar için kullanılması tavsiye edilmektedir.

Bu çalışma, pahalı bir yöntem olmasına rağmen sabit tip gürültü korelatörlerinin sızıntıların yüzeye çıkmama ihtimali bulunan karstik bölgelerde fiziki su kayıplarının başarılı bir şekilde yönetilebileceğini göstermektedir. Yöntem özellikle doğru CBS verilerinin bulunduğu ancak SCADA vb. uzaktan veri toplama ve kontrol sistemi bulunmayan, hidrolik modelleme çalışmaları yapılmamış içme suyu şebekelerinde fiziki su kayıplarının yönetiminde bir avantaj sağlamaktadır. Buna ek olarak, klasik akustik dinleme yöntemlerine göre daha hızlı ve etkilidir. Sistemde verilerin kaydedilmesi nedeni ile sık kayıp kaçak oluşan noktaları sistemden izlemek ve belirlemek daha kolaydır ve bu açıdan şebekedeki hassas noktaların tespitinde faydalıdır. Ayrıca, karstik akiferlerde içme suyu şebekesinde oluşan sızıntılarının tamamının yüzeye çıkmaması nedeni ile oluşan arızaların tespit ve tamirat süresini kısaltmaktadır.

\section{Teşekkür}

Bu çalışma kapsamında kullanılan verilerin tamamı ASAT Genel Müdürlüğü çalışmalarından temin edilmiştir. Yazar; ASAT Genel Müdürü Sayın Av. İbrahim Kurt ve ASAT Genel Müdür Yardımcısı Sayın Osman Yıldız'a bu çalışmaya imkan tanıdıkları ve katkıları için teşekkürlerini sunmaktadır.

\section{Kaynaklar}

Adedeji, K. B., Hamam, Y., Abe, B. T., \& Abu-Mahfouz, A. M. 2018. Pressure Management Strategies for Water Loss Reduction in Large-Scale Water Piping Networks: A Review. Springer Water, 465-480.

DOI:10.1007/978-981-10-7218-5 33.

Gupta I.A.D. and Kulat K. 2018. Leakage reduction in water distribution system using efficient pressure management techniques. Case study: Nagpur, Water Science and Technology: Water Supply.

DOI:10.2166/ws.2018.023

Hunaidi, O. and Wang, A. 2006. A new system for locating leaks in urban water distribution pipes. Management of Environmental Quality: An International Journal. DOI:10.1108/14777830610700928

Inan, N. 1985. The features and genesis of Antalya travertine. Jeoloji Mühendisliği Dergisi, 24, 31-37. 
Karadirek I.E., Kara S., Yılmaz G., Muhammetoğlu A., Muhammetoğlu H. 2012. Implementation Of Hydraulic Modelling For Water-Loss Reduction Through Pressure Management. Water Resource Management, 26, 2555-2568.

Li, R., Huang, H., Xin, K. and T. Tao, T. 2015. A review of methods for burst/leakage detection and location in water distribution systems. Water Science \& Technology: Water Supply.

DOI:10.2166/WS.2014.131.

Sánchez, E.H., Ibáñez, J.C. and Cubillo, F. 2005. Testing Applicability and Cost Effectiveness of Permanent Acoustic Leakage Monitoring for Loss Management in Madrid Distribution Network.

Corpus ID: 114616560

SKKY 2014. İçme Suyu Temin ve Dağıtım Sistemlerinde Su Kayıplarının Kontrolü Yönetmeliği, Türkiye Orman ve Su İşleri Bakanlığı, Resmi Gazete Sayısı 28994.

\section{internet kaynakları}

1-http://www.tuik.gov.tr, (29.11.2020)

2-https://www.asat.gov.tr/tr/kurumsal/faaliyet-raporu25.html, Faaliyet Raporu ASAT 2018 (29.11.2020) 